\title{
En estado de resistencia: la reciente narrativa hispanoamericana de mujeres*
}

\section{In State of Resistance: The Recent Women's Hispanic- American Narrative}

\section{Resumen}

El mundo vive un momento de efervescencia social y política, en que las demandas feministas han cobrado especial fuerza y vigor en distintos ámbitos de la vida, entre ellos en el mundo literario y cultural. El siguiente artículo se hace eco de este momento e indaga en las construcciones autoriales femeninas, principalmente a partir de conceptos como comunalismo (en la línea de los planteamientos de Cristina Rivera Garza), sororidad y genealogía. Para ello recoge algunas propuestas de las antologías Tsunami -título bajo el cual la editorial Sexto Piso publica en México (2018 y 2020) y luego en España (2019) sendas compilaciones- y Avisa cuando llegues (2018), antología chilena que recoge trabajos vinculados con la aparición de la mujer en el espacio público.

Palabras claves

Autoría; feminismo; sororidad; genealogía; comunalismo.

\begin{abstract}
The world is living times of social and political unrest and the feminist demands have gained strength and vigour in different spheres of life, including the literary and cultural world. This

* Este artículo ha sido escrito en el marco de los proyectos FONDECYT REGULAR 1180522 "Carto(corpo)grafías: narradoras hispanoamericanas del siglo XXI", PIA ANILLOS SOC180023 "The production of the gender norm" y Creación y Cultura Artística de la Pontificia Universidad Católica de Chile 2020-65087215 "Contemporáneas: Conversaciones con narradoras hispanoamericanas (después del tsunami)".
\end{abstract}


article echoes this moment and explores the female authorial constructions, from concepts as communalism (according to the ideas of Cristina Rivera Garza), sisterhood and genealogy. To that end, the article gathers some proposals from the anthologies Tsunami -name under which the publishing house Sexto Piso published in México (2018 and 2020) and then in Spain (2019) the three compilations - and Avisa cuando llegues (2018), Chilean anthology that compiles writings related to the proliferation of women on the public space.

Keywords Authorship; feminism; sisterhood; genealogy; communalism.

... y en mis oídos retumba el eco de esos versos del himno de Vivir Quintana: "Si tocan a una, respondemos todas...". ¿Cómo respondemos? ¿Con la voz entrecortada? ¿Con el cuerpo? ¿Con la lata de aerosol? ¿Con un coctel molotov? ¿Con toda nuestra rabia? ¿Con nuestra inteligencia? ¿Con todo lo que tenemos y somos? ¿Cuántas formas posibles de respuesta hay? Tantas como nosotras.

Gabriela Jáuregui, Tsunami II

Cualquier discusión que implique categorías como la de "narrativa de mujeres", necesariamente debe ser acompañada de un posicionamiento crítico que evidencie los peligros de pensar esta producción desde una óptica sesgada por el binarismo moderno y una visión de mundo heterocispatriarcal: ¿qué es, si no, el signo "mujer", tejido en una red de jerarquizaciones y oposiciones esencialistas y naturalizadoras de la heteronorma? Diamela Eltit advertía sobre esta "biologización" de la cultura hace ya casi 20 años, en diversos textos como éste, leído en Casa de las Américas, en que plantea, además, la relación entre biologicismo y mercado:

podría ser oportuno [.. .] referirme a la problemática abierta entre género y literatura. Ya el mercado se ha apropiado de esa disyuntiva. Bajo el 
prisma de la diferencia, se ha rediseñado inteligentemente el gueto. En realidad no se trata de literatura de mujeres — digo, el posible y complicado desentrañamiento de su cifra—, sino más bien de producir una literatura que sea apta para el consumo de mujeres, me refiero a relatos que hagan viable la proliferación de sus modelos mercantiles. Y así se vuelve a segmentar lo literario para mantener la hegemonía. De esa manera permanecen incólumes la literatura (con mayúscula) y su conservador programa. Y en otra orilla - que no puede sino ser comprensiva - la aglomeración de lo que se entiende por literatura de mujeres. Como apéndice. Así, sencillamente, apelando a la sociología de la letra.

[...] Asistimos a la biologización de la cultura. Esa cuota cosmética y políticamente pertinente que requiere la segmentación y clasificación de los mercados con el fin de intensificar sus ventas. (párr. 39-40)

No solo el biologicismo y las determinaciones del mercado oscurecen o complican la escena; en Latinoamérica es imposible afrontar la discusión sin circunscribirla al espacio colonial. Los feminismos latinoamericanos se apropian y al mismo tiempo encaran al pensamiento eurocéntrico, en una tensión que resiste el coloniaje epistémico. Es por esto que no es posible hablar de la escritura de las mujeres como si se tratara de un continuum o una producción homogénea, ignorando la densa trama de escrituras, lenguas y subjetividades sometidos a la normalización de los cuerpos y experiencias y presentes también en las disidencias sexo-genéricas. Todas estas subjetividades se rebelan y resisten la discriminación en sociedades donde priman los discursos colonialistas, clasistas, racistas y violentos, que muchas veces acotan la lucha feminista a la experiencia de una élite de mujeres.

¿Por qué, entonces, si se advierten todos estos matices, insistir en hablar de una "narrativa de mujeres" o una "literatura de mujeres", por qué insistir en "el ghetto"? Quizás sea porque la condición de posibilidad de una revisión de la historia literaria y de las tradiciones críticas locales, pase por concebir estas categorías 
estratégicamente, y no como la consecución de un fin o la constatación de un hecho originario. Tal es el argumento que por ejemplo esgrimen Andrea Kottow y Ana Traverso en el ensayo Escribir \& Tachar. Narrativas escritas por mujeres en Chile $(1920-1970)$ :

al movilizar una vez más una categoría que puede sonar algo empolvada, ofreciendo una lectura de "narrativas escritas por mujeres", no lo hacemos impulsadas por la certidumbre de que existe efectivamente una diferencia esencial entre hombres y mujeres, o en lo que escriben unos u otras. Más bien, pensamos la noción desde su potencial estratégico. (8)

Habría que preguntarse si esta estrategia, muy válida en el caso de escrituras históricamente invisibilizadas, lo es también en el caso de las obras que se producen hoy, en el siglo XXI. Aquí, la situación se complejiza, porque las condiciones de visibilidad del trabajo autorial de mujeres son distintas. Considero que palabras como "invisibilización", "silenciamiento", "mordaza” o "minorización” deben ser utilizadas con cuidado, porque si bien las mujeres no reciben aún un trato igualitario y respetuoso en el campo cultural, la utilización de eslóganes, hashtags, e imágenes que llegan a grandes grupos de lectores/consumidores, así como una creciente toma de conciencia de las políticas feministas, impactan en la creación, circulación y recepción de sus obras de modos impensados hasta hace unas décadas. Tomo también, en esta línea, la advertencia que hace la crítica Mónica Barrientos: “[...] sabemos que la invisibilización no es sólo la subexposición, la censura, el silenciamiento, el desprecio, sino también la sobreexposición, el espectáculo, la piedad mal entendida, el humanitarismo gestionado con cinismo" (Barrientos párr.7). En este sentido, no todas las escritoras sufren hoy una misma "opresión" o "invisibilización", sino que, por el contrario, muchas deben enfrentar la sobreexposición y también la incomprensión o más bien el manejo oportunista de los medios de comunicación y el mercado. 
Aun así, no parece impertinente volver, como lo hacen Kottow y Traverso y muchxs otrxs investigadorxs, a la noción de "literatura de mujeres", buscando agrupar de este modo escrituras y estéticas que han sido negadas o silenciadas en la tradición moderna eurocentrista y que todavía hoy se ven afectadas por el desconocimiento, la misoginia y otras lacras que no han desaparecido del campo cultural. Se trata de una forma de operar con una estrategia que en la agenda feminista constituye solo una de muchas que buscan reivindicar a sujetes en estado de resistencia. ${ }^{1}$ Aquí pienso esa resistencia a partir de la concepción de María Lugones, quien la define como "la tensión entre la subjetificación $[\ldots]$ y la subjetividad activa, ese sentido mínimo de agencia requerido para que la relación oprimir $\rightarrow \leftarrow$ resistir sea de tipo activo, sin apelación al máximo sentido de agencia del sujeto moderno" (109). Este tipo de subjetividad se expresa por lo general "infra-políticamente", y no "públicamente", ya que a las subjetividades resistentes le son negadas "legitimidad, autoridad, voz, sentido y visibilidad" (Lugones 109). En el ámbito colonial, particularmente en Latinoamérica, la multiplicidad de estas experiencias se ha visibilizado recién en las últimas dos o tres décadas a través de una ingente producción que reivindica lugares de enunciación propios, y con un carácter de urgencia. El estado de resistencia es una actitud, una forma de enfrentar la violencia que cotidianamente se ejerce desde los discursos y prácticas hegemónicas que procuran encapsular, borrar y liquidar las diferencias.

En este escenario, producir espacios de apertura a la diversidad, sobre todo en la literatura, un ámbito de por sí elitista y patriarcal, no resulta una tarea fácil, toda vez que el mundo literario se desarrolla en el espacio público, es particularmente conspicuo y alimentado por criterios y valores patriarcales. Por lo demás, la relectura del canon, su desmantelamiento y reinvención, opera desacompasadamente. En las últimas décadas, al menos en América Latina, se han rescatado con mayor rapidez las autorías de escritoras provenientes de grupos de

\footnotetext{
${ }^{1}$ Antes hemos empleado esta expresión con María José Punte y Fernanda Bustamante, para dar un marco al dossier "Narradoras latinoamericanas de las últimas dos décadas: voces, representaciones, estrategias", que coordinamos en conjunto para la revista Letral n 22 (2019).
} 
poder, blancas y de origen europeo, en tanto el trabajo de creadoras racializadas y signadas por su queeridad, se incorporan muy lentamente o los aspectos más subversivos de su trabajo han sido amainados en la discusión crítica.

Consideré necesario anteponer estos matices a una reflexión sobre el momento que atraviesa lo que llamaremos — por el momento y a modo de reivindicación de un espacio en construcción - la "autoría de mujeres" en Hispanoamérica. Y digo Hispanoamérica intencionadamente, por diversos motivos. En primer término, la relevancia que aún tiene, para lxs latinoamericanxs, el reconocimiento simbólico y la instalación material de las obras en el circuito cultural español. Es allí donde emerge la idea del "boom" latinoamericano y donde hoy se habla de un nuevo "boom" literario protagonizado por escritoras; ${ }^{2}$ es desde España que se construye en gran medida el poder simbólico de lxs autorxs más validados en los circuitos locales. Por otra parte, el surgimiento, hace veinte años, de pequeñas editoriales que realizan un importante trabajo curatorial, el flujo transfronterizo de los textos publicados por ellas y la gran presencia que actualmente pueden tener lxs escritorxs en las redes sociales, contribuyen a la conformación de una nueva escena literaria transnacional y transatlántica, con agendas asimismo internacionales, como ocurre en el caso de las reflexiones y demandas feministas que hoy impactan el campo cultural de un modo impensado hasta hace unos años. ${ }^{3}$

2 "El otro boom latinoamericano es femenino", titulaba El País, de España (2017) un reportaje que ha tenido sus epígonos latinoamericanos: en el diario uruguayo El observador -"El nuevo boom latinoamericano está escrito por mujeres" (2019) - o en la revista colombiana Arcadia, que sofisticaba un poco la reflexión: "¿El cuento es el nuevo "boom" entre las escritoras latinoamericanas?" (2019).

${ }^{3}$ Con esto me refiero no solo a la inclusión de nuevas temáticas, sino también a la reconfiguración del campo cultural y las posiciones ocupadas en él. Movimientos como el llamado \#MeToo, por ejemplo, han sacudido fuertemente el campo cultural mexicano (\#MeTooEscritoresMexicanos), denunciando una enorme cantidad de prácticas misóginas y abusivas, hasta hace muy poco naturalizadas en ese espacio de trabajo. Como explica Estefanía Camacho en un reportaje publicado por la revista Gatopardo, todo comenzó en marzo de 2019, cuando "miles de usuarias en Internet se sumaron al movimiento \#MeToo después de que un grupo de por lo menos 10 mujeres denunciaran al escritor Herson Barona en redes sociales como un agresor de mujeres" (párr. 1). El movimiento, según relata el reportaje, desbordó el espacio de Twitter y del mismo campo literario, ya que luego se produjeron denuncias vinculadas con la publicidad, la academia, el periodismo, el teatro, la música y las artes, entre otros. 
Sin embargo, esta aparente entronización de las escritoras es contradictoria: si bien cada día es más frecuente que sus textos y ellas mismas circulen en ferias, congresos y otras instancias, traducidas al inglés y a otras lenguas -lo se podría considerar como la "mundialización" de su escritura- ${ }^{4}$ esta circulación transfronteriza de las nuevas plataformas sociales y mediáticas o la deslocalización del trabajo editorial, no necesariamente contribuye a una inclusión y valoración efectivas de (todas) las autoras en los campos culturales locales e internacionales de los cuales ellas hacen parte.

Como un elemento más para la discusión, se puede tener en cuenta que en esta escena de emergencia de textos, nombres y voces, protagonizada por decenas de creadoras como Valeria Luiselli, Fernanda Melchor, Laia Jufresa, Verónica Gerber, Alejandra Costamagna, Lina Meruane, María Gaínza, Mariana Enriquez, Samanta Schweblin, Mónica Ojeda, Fernanda Trías, Margarita García Robayo, Rita Indiana, Yolanda Arroyo, Claudia Hernández, Sara Mesa, Elvira Navarro, Gabriela Wiener, ${ }^{5}$ solo por mencionar a algunas de las más consolidadas, intervienen también los criterios de mercado y la agenda de los medios de comunicación. Desde luego, quedan muches otres excluides, de acuerdo con una conformación de campo que jerarquiza y ordena géneros y subgéneros literarios, ficción y no ficción, e incluso temas y formas específicas de narración. Es así como incluso hoy, de cara al aparente "éxito" de las escritoras y de los discursos antes minorizados, muchas veces lo que hay detrás son intereses económicos y perspectivas políticas que, lejos de visibilizar y valorizar la disidencia, procuran domesticar las propuestas más radicales para alimentar lo que tanto Diamela Eltit como otrxs autorxs ven como

${ }^{4}$ Jorge Locane ofrece un interesante análisis sobre la relación entre literaturas locales y mundiales. Interroga la definición de David Damrosch de literatura mundial como aquella que circula más allá de su cultura de origen, ya sea en la traducción o en su propia lengua (Locane 190) y se pregunta por el fenómeno de lo "no circulante", lo ausente. Pone en evidencia las relaciones entre literatura mundial e industria cultural y transnacional, cuestiones que también podrían ser sopesadas de cara a la circulación transfronteriza de antologías como las que aquí abordaré, pero esto excedería el propósito de mi artículo.

${ }^{5}$ Menciono a algunas de las autoras que forman parte del corpus de trabajo de mi investigación, que recoge a más de cien autoras de diversos países, seleccionadas a partir de dos criterios: nacidas con posterioridad a 1970 y autoras de al menos dos libros de circulación transnacional. 
una intensificación del programa neoliberal, con la consecuente proliferación de nichos de consumo que pueden acabar por convertir las consignas sociales en nuevas mercancías, y algunas reivindicaciones, en formas de discriminación o ghettización.

Discernir sobre estos procesos es complejo, ya que ocurren a la par de las legítimas demandas de inclusión y equidad de género, que en el programa del feminismo liberal remiten, en la mayoría de sus formas, a la exigencia de cuotas participativas y suministro igualitario de fondos privados y públicos. En este sentido, la distancia de estas posturas respecto de los movimientos sociales y los sectores más disidentes del feminismo puede ser abrumadora, también en el campo cultural. Hay sectores para los cuales un "cuoteo" de la participación de las escritoras en premios, jurados, proyectos y festivales - que por cierto aún no alcanza equidad alguna, pues el reconocimiento para las autoras sigue siendo muy menor al de sus pares varones, heterosexuales y cisgénero- ${ }^{6}$ no resuelve problemas mucho más de base, que tienen que ver con cuál es el lugar que se le asigna a la escritura de mujeres, entre otres sujetes, en el relato hegemónico de la literatura... y de la "nación".

\section{Autorías de mujeres}

El concepto de autoría para abordar la producción escrita por mujeres permite revisar diversos aspectos vinculados no solo con la conformación del canon, sino también con cómo se producen los conceptos literarios. En una recopilación muy reciente e imprescindible sobre este tema, las ensayistas y académicas Aina Pérez y Meri Torras se preguntan ¿Qué es una autora? (2019), aludiendo con esto a la famosa pregunta de Michel Foucault "¿Qué es un autor?"

\footnotetext{
${ }^{6}$ Me refiero en detalle a esta asimetría aún existente en el artículo "Autoría femenina y autoficción en la narrativa latinoamericana reciente". En: Samperio, Daniel y Christian Sperling (Eds.). Desafios y Debates para el Estudio de la Literatura Contemporánea. Universidad Autónoma Metropolitana - Azcapotzalco, México (en prensa).
} 
(1969) y al texto anterior de Roland Barthes, el famoso artículo "La muerte del autor" (1968). La pregunta, como bien lo advierten las investigadoras Pérez y Torras, admite muchos más grados de incertidumbre: ¿qué es ser una autora latino/hispanoamericana? E incluso, más específicamente, ¿qué es ser una autora latino/hispanoamericana y ser, también, feminista? ¿Y qué significa todo esto en tiempos de insubordinación y estallidos sociales, como los que se están viviendo a lo largo de toda Hispanoamérica?

Más que preguntarnos qué es una autora, habría que pensar cuáles son las condiciones de existencia de una autoría. Pérez y Torras definen por ello el concepto atendiendo a su carácter contingente, como un "conjunto de representaciones e interpretaciones que configuran al creador/a como un ser imaginario de géneros y uso colectivos; y como el conjunto de normas y relato culturales que determinan qué es un autor y moldean aquellas representaciones e interpretaciones" (12). Esto evita la confusión con la persona del autor/a (si bien la persona del autor está sujeta a los mismos vaivenes culturales) y propicia la remisión a un imaginario y un mundo de representaciones y relatos en que los contextos políticos e históricos específicos son fundamentales en la normalización de la autoría.

Las escritoras han debido llevar adelante un difícil camino de individuación. Nathalie Heinich hace hincapié en la inscripción habitual de las mujeres, en los imaginarios artísticos y literarios, como creadoras colectivas, en las antípodas del "régimen de singularidad" que caracteriza a la autoría masculina, "universal" (cit. en Pérez, Torras y Cróquer). Más del lado de la artesanía y de la recepción de las obras y no de la "genialidad" y poder creativo asignado a los varones, las mujeres eran vistas sobre todo como comparsas pasivas. Tal vez por esto sea difícil todavía lidiar con las imágenes compuestas por los medios, de escritoras caracterizadas por clichés sexistas que exaltan la juventud, la belleza o la domesticidad en la construcción de sus rasgos autorales, y no sus singularidades y sensibilidades intelectuales y poéticas. 
Ya en otros espacios he citado y compartido el análisis de la crítica mexicana Nattie Golubov, ${ }^{7}$ quien escribe, de cara a este fenómeno, que "las escritoras no son dueñas de sí mismas" (42). La intervención de las maquinarias editoriales, la proliferación de imágenes mediáticas y la importante aparición de las redes sociales impiden tener un control absoluto de la propia imagen. Algo de esto se puede apreciar en numerosas notas de prensa en que todavía abundan, a pesar de su incorrección política, los detalles sobre la apariencia física de las escritoras. Solo dos ejemplos chilenos: un reportaje de 2015 sobre la emergencia de nóveles autoras, titulado "Las nuevas chicas del barrio", firmado por Roberto Careaga, en que Paulina Flores es presentada como "Rubia oxigenada de look aún confundible con el de una adolescente" (párr. 1), o la reseña del libro Usted está aquí, de la colombiana Margarita García Robayo, que el crítico Juan Manuel Vial titula "Hembras de armas tomar" y que comienza así: "Los cuentos de la colombiana Margarita García Robayo, llamada 'la escritora sexy' por cierta prensa de su país, son llamativos y cautivantes de entrada" (párr. 1). La alusión a "cierta prensa" no termina de encubrir su propia fascinación por esta imagen de "escritora sexy", que parece incidir en la calificación de sus relatos como "llamativos y cautivantes". El uso de verbos y adjetivos sexistas no es un problema del siglo XX: sigue estando a la vuelta de la esquina en el campo cultural y las mediaciones periodísticas.

$\mathrm{Si}$ bien las autoras pueden manifestar su disgusto por el sesgo de entrevistadores y críticos, esto no obsta para que el campo siga expresando la dominación masculina, heterosexual y cisgénero que procura aplacar el

\footnotetext{
${ }^{7}$ Cuando proyectaba este texto, decidí escribir la columna "Cómo se construye una autora. Algunas ideas para una discusión incómoda" a raíz de un intercambio de opiniones en Twitter en que me pareció se tocaban muchos puntos atingentes a mi investigación. El texto fue publicado en agosto de 2020 en la revista de divulgación cultural Palabra pública y desató una serie de respuestas de escritoras y críticas en mi país, en México y también en España, entre agosto y septiembre de 2020. En la columna me refería al texto de Golubov entre otros y abordaba los problemas que expongo en este artículo, pero desde una óptica más local (y polémica). Más tarde volví sobre el tema en la conferencia de cierre del Coloquio "¿Cómo ser escritora? Género y autoridad en el campo literario contemporáneo", efectuada en octubre de 2020. El texto de esa conferencia se publicará en la revista española Pasavento y allí me refiero a la "polémica" y a las preguntas que abrió mi ensayo de divulgación, referidas al problema de las autorías de mujeres, pero también a la relación entre crítica literaria, academia y activismo, entre otras aristas que reveló aquel intenso intercambio.
} 
protagonismo y la potencia subversiva de subjetividades "otras", tributarias o ancilares respecto de la contribución tradicionalmente "masculina". Es quizás por esto que hay autoras que evitan encasillar su escritura como "femenina" y/o "feminista": porque temen exclusiones u observan que estos conceptos han sido en sí mismos negativizados (la asimilación de "feminazi" para decir "feminista" es solo un ejemplo de ello). Mariana Enriquez ofrece un ejemplo en esta entrevista de 2017:

\section{¿Cuál es la pregunta qué más odias?}

Cualquiera relacionada con la literatura femenina.

\section{¿Por qué?}

Porque es sexista. Hay quienes te van a decir que la mujer durante muchos años no tuvo acceso a la alfabetización y a la producción literaria, que no estuvo retratada en la literatura, y eso es cierto y lo lamento, pero hoy no es raro y yo me niego a que me pongan en un lugar de raro.

\section{¿No hay literatura femenina?}

No.

Pero estarás de acuerdo en que hay cierta literatura que gusta más a las mujeres y otra a los hombres.

Pero el mercado es quien lo determina así. Es una cuestión de temas, de géneros literarios. Los hombres por ahí prefieren más el policial. Pero hay hombres que no leen mujeres por prejuicio.

\section{¿Te ha pasado?}

Sí, alguna vez me lo han dicho, porque creen que hay algo de la experiencia de la mujer que a ellos no les va a interesar, lo cual es raro, porque, por ejemplo, los mejores autores de policial son mujeres, creo yo. Patricia Highsmith y tantas otras.

\section{¿Dónde más notas el machismo?}

En los eventos, antologías, festivales. No te ponen en una mesa con hombres. Tiene que ser la mesa de mujeres, aun cuando nuestros géneros 
narrativos no tengan nada que ver. Me encantó que ayer me presentara Álvaro Bisama y no, por ejemplo, Alejandra Costamagna, que es mi amiga y también estaba ahí.

Es indudable que Enriquez escribe sobre experiencias de las mujeres (son numerosas las protagonistas de sus cuentos que deben lidiar con situaciones adversas en gran medida a causa del patriarcado) y no solo eso: sus libros tienen una clara impronta feminista, ya que pone en jaque mate el binarismo, la heteronorma e incluso las tradicionales asociaciones a las que ella misma se refiere, entre binarismo y géneros literarios. Por lo mismo, ¿se podría decir que Enriquez "no es feminista" solo por lo que plantea en sus respuestas, en que de hecho ella denuncia el "sexismo" de la pregunta por una escritura de mujeres? ¿No hay, asimismo, en el temor al ghetto, una legítima preocupación de las escritoras? ¿Por qué lidiar con miradas parcializadoras o estigmatizadoras de su trabajo, a diferencia de sus contemporáneos varones, inscritos en circuitos de trabajo y publicación "universales"?

Una comprensión simplista y binaria de estos temas podría acarrear, asimismo, una inapropiada inscripción política "feminista" en el caso de algunas literaturas que, lejos de favorecer un programa de visibilización y reconocimiento, se ajustan a paradigmas expresivos y representativos poco novedosos, irrelevantes o incluso patriarcalizados. Desde un marco postestructuralista, Nelly Richard proponía, hace ya varios años, no solo la ruptura de modelos de identificación binarios, sino que también la reincorporación de "la escritura de mujeres a las dinámicas de entrecruzamiento polémico de las múltiples serie discursivas e ideológicas que animan las tradiciones lierarias del texto" (21), lo que desde su perspectiva reorienta la crítica feminista a pensar "lo femenino" ya no como una identidad esencial sino "en tensión con el marco de la intertextualidad cultural, y

\footnotetext{
${ }^{8}$ Paz María Zúñiga analiza a fondo esta cuestión en la tesis de Licenciatura en Estética “¿Estética feminista?: poética y construcción narrativa en Las cosas que perdimos en el fuego, de Mariana Enriquez" (2019).
} 
no como una dimensión pura y homogénea que se mantendría aislada de los procesos de institucionalización de la cultura" (21).

Las actuales teorías performativas del género, pero también los activismos que comprometen miradas interseccionales y postcoloniales rebeldes respecto a la normalización de las subjetividades, se acompañan de reflexiones sobre las marcas, remarcas y apropiaciones del feminismo y sobrepasan la pregunta por el sexo de la escritura, como también la esquemática repartición de las literaturas "femenina" y si hubiere tal cosa, "masculina" (nunca ha sido marcada de esta forma porque se considera "universal"). En este escenario, parece importante relevar propuestas feministas que exploran el ámbito de la escritura tratando de transformar, con nuevas voces o modos de trabajo, los espacios de sociabilidad y la construcción de la historia y la crítica literarias.

\section{Las "pedagogías de la crueldad" y el feminismo "de los zulos"}

Aparecidas bajo el sello de editorial Sexto Piso en México (2018 y 2020) y en España (2019), las tres antologías de nombre Tsunami agrupan textos feministas, cuyas autoras, de edades entre los veinte y más de ochenta años, escriben sobre sus experiencias y las de otras mujeres; en el caso de México, se pone énfasis sobre todo en el difícil campo literario. El nombre escogido se hace eco de la idea que vivimos, más que una cuarta ola feminista, un tsunami de proporciones, que reúne con fuerza a mujeres de diversas generaciones y modos de pensar, con ánimos de arrasar estructuras largamente instaladas; como lo plantea la escritora mexicana y coordinadora de ambos volúmenes en México, Gabriela Jáuregui, “el sentimiento es que, en estos tiempos, nuestras voces se suman en crescendo hasta que ola tras ola más bien se crea un verdadero tsunami” (Tsunami I 9). Las autoras convocadas en este primer volumen son Brenda Lozano, Vivian Abenshushan, Cristina Rivera Garza, Daniela Rea, Dania J. Torres, Jimena González, Margo Glantz, Sara Uribe, Verónica Gerber Bicecci, Yásnaya Elena Aguilar Gil y Yolanda Segura. En el 
segundo volumen participan Marina Azahua, Lydia Cacho, Dahlia de la Cerda, Diana del Ángel, Lia García (La Novia Sirena), Valeria Luiselli, Fernanda Latani M. Bravo, Luna Marán, Sylvia Marcos, Ytzel Maya, Brenda Navarro y Jumko Ogata. $^{9}$

En ambos volúmenes las escritoras indagan en las experiencias de género desde una perspectiva feminista y sobre todo autobiográfica. Me referiré particularmente a aquellas que proponen lecturas sobre la experiencia y el campo literario, así como sobre su modus operandi, abogando por nuevas formas de convivencia y de comprensión del trabajo escritural. Sobre todo me interesa la aparición de algunos conceptos en los ensayos de Jáuregui, Vivian Abenshushan y Dahlia de la Cerda, que complementaré con otras lecturas.

Jáuregui plantea un marco para la discusión acorde con las problematizaciones antes expuestas. Sus preguntas abarcan experiencias transfeministas, queer y no-binarias: "yo volvería a insistir en aquellxs cuyo género va más allá del binario o de las definiciones cisexistas de mujer o de lo femenino en su sentido más cerrado y conservador" (84). Se pregunta cómo escribir "hackear" el lenguaje para hacerlo "nuestro": “¿Cómo contamos nuestra insubordinación?" (82). Propone sobre todo pensar los espacios virtuales que hoy ofrece la tecnología como espacios subversivos. “Cómo hacer para no caer en las

\footnotetext{
${ }^{9}$ Me atrevo a proponer que este libro se diferencia de antologías que emergieron en los 90 buscando exaltar la literatura escrita por mujeres. Un caso significativo fue el de tres antologías sobre la maternidad: Madres e hijas (España, Anagrama, 1996), Salidas de madre (Chile, Planeta, 1996) y Salirse de madre (Argentina, Croquiñol, 1989). Nora Domínguez ofrece una rápida y contundente comparación entre los libros argentino y chileno: en tanto el primero es autogestionado por un colectivo de autoras en cuyas biografías, dice, "se leen distintas formas de la militancia feminista" (165), el libro chileno, como el español (en que ya desde el título se pierde el sentido rupturista de la antología bonaerense), resulta de un encargo editorial. Domínguez resalta en la presentación de este libro que se subraye que "somos mujeres quienes constituimos un $80 \%$ del mercado editorial" (165), lo que deja al descubierto los razonamientos que orientaron la compilación, la que seguramente fue pensada por la transnacional para llegar a un nicho de consumidoras. Del libro argentino, Domínguez destaca, por el contrario, lo que me parece ver en las antologías a las que me referiré a continuación (sobre todo los en los Tsunami mexicanos y Avisa cuando llegues): "lo más destacable es el carácter colectivo de esta práctica de escritura feminista y el hecho de poner a circular y abrir, a través de la publicación, los sentidos diversos que puedan colocarse en la maternidad". Aunque con calidades "disímiles" había un propósito político explícito en la elección del tema de la maternidad, uno de los puntos en disputa del feminismo, por ser una institución criticada, resignificada y también, en algunos casos, exaltada.
} 
trampas del conservadurismo capitalista ni de la desesperanza opresiva que caracterizan las actividades en la red?", se pregunta, como muchxs que hoy buscan en las redes e Internet herramientas con las cuales construir nuevas formas de convivencia aun cuando sabemos que grandes corporaciones manejan y trafican información y poder a través de estos espacios.

Más específicamente literarios aún son los textos de Abenshushan y De la Cerda, escritoras que también han destacado por su trabajo en la coordinación de talleres e iniciativas colectivas de escritura. Abenshushan traspone conceptos de Rita Segato al análisis del funcionamiento del campo literario para ahondar sobre todo en las experiencias vinculadas con el espacio de los talleres literarios, hoy uno de las principales fuentes de sustento de lxs escritorxs que procuran sostenerse económicamente realizando labores en el ámbito de la literatura (otras son la edición, la docencia universitaria, la gestión cultural, la distribución y venta de libros). Abenshushan describe vívidamente las "pedagogías de la crueldad" que debe enfrentar una escritora en el cadalso de estos talleres y desde entonces, durante el resto de su proceso formativo:

La joven escritora (la jovencita, la apodan todos) no ha podido seguir leyendo en voz alta su texto. Es el primero que lleva a la sesión (o ritual de desollamiento) y será probablemente el último [ . . ] Esto no es un ensayo, dice el primero. Esto no es literatura, argumenta el segundo. Te falta rigor, hilación, ¡voz propia!, cantan los terceros... La escritura ha pasado por el tribunal. Ella es la acusada. ¿Cuál es su crimen? No escribir bien [. . . ] Sobre todo: no soportal virilmente la crítica. (12)

Abenshushan describe y cuestiona la idea de que la letra "con sangre entra"? ¿Por qué soportar estas vejaciones? ¿Qué ocurrirá con la protagonista de esta historia, se convertirá ella misma en verdugo en cuanto pueda? La lectura de Abenshushan es válida tanto para ese espacio de los talleres como para toda construcción pugilística del campo cultural: "el taller literario [...] opera menos 
como un espacio de diálogo o trasmisión de saberes, que como la escuela que produce (y reproduce) el sistema literario como orden patriarcal" (13), lo que "normaliza el alfabeto de la humillación indispensable para bregar en la selva del mercado editorial" (13), que demanda, como enseña el taller de esta historia, "voces propias", la literatura como un bien de consumo, individualizado, singular y también productivo. ¿Qué hacer? La misma Abenshushan relata su experiencia como gestora de talleres literarios participativos, no jerárquicos. $\mathrm{Y}$ es que ella, como muchas escritoras, ha descubierto la necesidad de plantar cara frente a los modos de hacer competitivos, individualistas y destructivos a que estamos acostumbrades.

Dahlia de la Cerda aborda una arista algo distinta del quehacer literario. En "Feminismo sin cuarto propio", un ensayo autobiográfico y filosófico muy bien trabado y documentado, hasta cierto punto confrontacional e incómodo, rechaza la idea, simplista y demasiado popular, de que existe un solo feminismo que se opone a la opresión de las mujeres como si todas habitáramos un mismo tipo de experiencias. Considera perspectivas decoloniales y americanistas que ya antes he mencionado, y explica las tensiones que se producen entre los feminismos blancos y los feminismos "marrones", de mujeres no privilegiadas, racializadas y estigmatizadas por su clase social, asumiendo en su texto, con gran lucidez, la experiencia del resentimiento. Argumentativamente logra diferenciar con mucha claridad teoría, praxis, agenda y reivindicaciones feministas y, en la arena literaria, propone diferenciar los feminismos del "cuarto propio", con origen burgués y eurocéntrico, en que el cuarto es signo de privilegio, de su antítesis, los "zulos" (escondite, habitáculo oculto y estrecho), idea que toma de la activista vasca Itziar Ziga, autora de Un zulo propio (2010). En su texto soplan aires de manifiesto cuando, parafraseando el comienzo de Teoría King Kong (2006), de Valerie Despentes, establece con quién y por qué construir su elocución:

Escribo para las que perrean sucio y hasta abajo. Escribo para las que riman en su lengua materna en protesta a la imposición del español. 
Escribo para las que no leen a señores blancos que quieren explicar el mundo sin haberse ensuciado los zapatos. Escribo para las que abortaron mientras trabajaban doce horas en una tienda de zapatos. [...] Escribo para las que dicen haiga. Escribo para las que agregan nos al final de todos los verbos. [...] Escribo, sobre todo, para las que no quieren ni hablar ni escribir el español como lo indica la real academia de la lengua. Escribo para las que no tienen cuarto propio. (Tsunami II 62)

El mismo proceso de elaboración del ensayo es "sin cuarto propio": "y entre cuartilla y cuartilla me daba mis tiempos para bailar las de Winsin y Yandel. Las de Ivy Queen y las de Tego Calderón. Esto no es anecdótico. Es político" (62-63), reivindicación del reggaetón desde un feminismo plebeyo, "de zulo". De la Cerda recoge tradiciones de pensamiento feminista para las cuales pensar solo desde los lugares de privilegio provoca distorsiones en el análisis, incluso en la misma comprensión del patriarcado, desvinculado de matrices que no sean la jerarquización sexual. En este sentido, le interesa explicar cómo opera el pensamiento hegemónico privilegiado:

[...] desde luego que, si eres un hombre blanco, heterosexual, clase media/alta, guapo y no perteneces a la diversidad funcional los movimientos identitarios deben parecerte una estupidez porque tú perteneces a una hegemonía y eres la norma y la medida. Aplica también para las mujeres. Sobre todo, para las feministas blancas y de clase media y guapas que dicen que no existen varios feminismos sino un feminismo: el feminismo que lucha contra la opresión. Así, en singular, como si existiera una sola opresión. Esas feministas del cuarto propio afirman que el feminismo negro no es necesario porque dividirnos entre negras y blancas nos separa. Sí, las personas que dicen que los movimientos identitarios no son importantes son las mismas que dicen no veo negros ni blancos ni jotos ni lesbianas ni hombres ni mujeres: veo personas. (78-79) 
De la Cerda busca diferenciar así la praxis feminista de una malentendida sororidad: "La praxis es fácilmente confundida con la amistad, abrazar a tu amiga no es una praxis feminista, es una manifestación de cariño" (81). Todo esto resulta de interés para las estrategias y demandas feministas en el ámbito cultural, ya que en Latinoamérica las estrategias culturales debieran hacerse cargo tanto de la jerarquización sexual como de su evidente conexión con la jerarquización racial y la social (88). La importancia estructural de la ciudad letrada en el establecimiento de las relaciones coloniales invita a pensar seriamente la estructura de privilegios que funciona como resorte de inserción autorial.

En el Tsunami español, donde participan las escritoras Pilar Adón, Flavita Banana, Nuria Barrios, Cristina Fallarás, Laura Freixas, Sara Mesa, Cristina Morales, Edurne Portela, María Sánchez y Clara Usón con textos principalmente narrativos y autobiográficos (a diferencia del mexicano, donde es posible hallar desarrollos más ensayísticos), la editora y prologuista Marta Sanz hace precisamente un llamado muy propio de ese feminismo blanco del que habla De La Cerda, poniendo de relieve especialmente el carácter sororo del libro: “Cada vez más mujeres queremos juntar relatos con los que mirarnos y remirarnos para reconstruirnos. A nosotras y a las nuestras. Por mí y por todas mis compañeras" (Sanz 12-13). El propósito de la frase es bienintencionado, pero complejo: "nosotras”, ¿somos todas las mujeres, más allá de nuestras diferencias políticas y éticas”. “QQuiénes son "las nuestras”? ¿A quiénes me siento compelida a "salvar”? Sobre este punto, si bien es bastante positivo que cada día se conformen más colectivos y redes de escritoras y creadoras vinculadas con el mundo del libro, tal vez sería conveniente afinar las posiciones de manera de poder leer estos posibles desencuentros políticos, que emergen sobre todo, a mi modo de ver, en torno a la idea de sororidad. En un valioso ensayo de Paula Biglieri y Luciana Cadahia, quienes buscan acercar populismo y feminismo a pesar de sus aparentes contradicciones -que se encargan de despejar — se refieren a este problema; ¿puede la política de la sororidad desestimar otras luchas sociales? ¿Qué pasa si la 
sororidad y la ética de los cuidados acaba por anular o invisibilizar los legítimos conflictos ideológicos que diferencian las estrategias feministas? Como plantean Biglieri y Cadahia, "there is a danger of turning the feminization of politics into an ethic of care that, by politicizing what has historically called 'domestic', runs the risk of turning the "domestic" - the sphere of reproduction of social life - into the only possible horizon of the political" (120). ${ }^{10}$ Este tipo de política de los cuidados es además una forma de negar los conflictos, "as if conflict and rupture fall on the masculine side, and reconciliation and closure of antagonism fall boardly on the feminine side" (120). ¿ ¿Se podría considerar "patriarcal” el disenso y la crítica de una feminista acerca de las proposiciones de otras feministas?

Estas preguntas y reflexiones son necesarias; de lo contrario, las demandas feministas pueden verse reducidas a eslóganes sin contenido preciso o peor aún, lejos de visibilizar la diversidad de las experiencias, borrarlas e ignorarlas. "La multiplicidad nunca se reduce”, escribía María Lugones:

¿No es cierto que experimentamos un sentido de reconocimiento tranquilo, pleno y sustancial cuando preguntamos: "¿Qué quieres decir con 'Nosotras', Mujer Blanca?” ¿No es cierto que rechazamos la oferta desde la posición de Sojourner Truth y que estábamos listas para rechazar su respuesta? ¿No es cierto que rechazamos la oferta en la diferencia colonial, seguras de que para ellas sólo había una mujer, una sola realidad? ¿No es cierto que ya nos conocemos unas a otras como veedoras múltiples en la diferencia colonial, concentradas en una coalición que ni comienza ni termina con esa oferta? (Lugones 116-117)

\footnotetext{
10 "Hay un peligro en convertir la feminización de la política en una ética del cuidado que, al politizar lo que históricamente se ha llamado 'doméstico', corre el riesgo de convertir lo 'doméstico' -el ámbito de reproducción de la vida social- en el único posible horizonte de lo político".

11 "como si conflicto y ruptura cayeran en el lado masculino, y reconciliación y cierre del antagonismo cayeran directamente en el lado femenino".
} 
Por lo mismo, y como lo he sostenido en otros espacios, pensando en la utilidad del concepto de sororidad para la literatura, debiéramos considerarlo más que una declaración espontánea de igualdad y solidaridad de "origen", un pacto que, reconociendo las diferencias, permita un acercamiento en el marco de un sentir militante. Mónica Barrientos lo explica de una manera más adecuada:

quiero desmarcarme de esa "comunidad imaginada" que integra sólo lo que se tiene en común, porque es así como se han forjado históricamente los grandes consensos. Apuesto por una comunidad entendida no bajo una esencia, sino, en palabras de Nancy, como un "estar en común" con el otro donde debe revalorizarse constantemente esa misma relación que no es un valor primordial o primigenio. (párr.8)

De todos modos, la idea de sororidad -que responde al concepto de "fraternidad" moderno y remarca que este último no es universal — puede ser muy fecunda con el fin de llevar adelante las demandas feministas, siempre que se construya con una conciencia interseccional y sin dejar de lado los diversos cruces políticos que inciden en la construcción de lo común. Ochy Curiel lo pone en estos términos:

¿Cómo comprender el contexto específico donde nos ubicamos que permita construir pactos políticos entre feministas de varios contextos sin que ello convierta en impunidades las desigualdades y diferencias que nos atraviesan por raza, clase, sexualidad, situación migratoria en los contextos y las mismas experiencias situadas? ¿Cómo actuar como feministas en los contextos latinoamericanos y caribeños atravesados por conflictos armados internos, desplazamiento forzado, pobreza extrema, racismo, violencia contra las mujeres y un "socialismo de siglo XXI" con tintes dictatoriales? (5) 


\section{Genealogistas}

Siguiendo con el planteamiento y buscando dar una forma más precisa a la "sororidad" literaria, me interesa particularmente relevar el trabajo de diálogo intergeneracional que ha permitido una reconsideración del pasado literario y que se puede interpretar como una forma específica de trabajo sororo.

Las escritoras buscan desestabilizar el canon tradicional de lecturas. Todo canon constituye una construcción elitista, excluyente e ideologizada. Para desmontar este tipo de construcciones hay dos opciones: la primera es cuestionar sus criterios y proponer relecturas que aborden las obras canónicas con una mirada nueva. La segunda opción es el levantamiento de contracánones. Por citar un ejemplo, la desaparecida revista cultural colombiana Arcadia publicó a fines de 2019 un listado de cien textos imprescindibles de autoras hispanoamericanas, con el fin de hacer ver el carácter disruptivo y muchas veces experimental de estas escritoras, que siendo incluso claves para la literatura en lengua hispana, no contaron con la lectura que merecían. Ejercicios como éste no son fáciles, porque siempre detonan alarmas de la crítica misógina que sigue fundamentando su invisibilización con argumentos “estéticos”. En Feminismo y arte latinoamericano. Historias de artistas que emanciparon el cuerpo, Andrea Giunta apunta a este problema de la crítica que, invocando criterios de "calidad", desplaza la lectura de obras realizadas por mujeres, algo que también ocurre en el ámbito literario. Giunta se pregunta a qué se refieren con "calidad" y sobre todo, cómo y quién la define. Está claro que tanto críticos como curadores, jurados y editores evitan responder a estas preguntas. Incluso en cartografías recientes de la literatura latinoamericana, se incluyen un número minoritario de narradoras en los listados y análisis (a menos que la cartografía sea, estrictamente, de mujeres), sin que se haga alusión al hecho 
de que hoy existe una enorme emergencia de temas, formas, soportes y estrategias asociadas a esta presencia más sostenida. ${ }^{12}$

De esta forma, como denuncian Aina Pérez y Meri Torras, se va creando la ficción de un mundo de escritoras sin continuidad entre ellas, para mostrar que cuando aparece una buena es algo totalmente excepcional, fuera de norma. Esto hace de ellas "monstruos" autoriales. Para brillar, hay que hacerlo sin referentes y sin tradiciones femeninas, al menos. Pérez y Torras plantean la posibilidad de contrarrestar este efecto a través de la articulación de una genealogía autorial que establezca “'los espacios de intersubjetividad femenina' cortocircuitados por la tradición crítica patriarcal" (14 María-Mercè Marçal en Pérez y Torras).

Actualmente, en tiempos de Internet $\mathrm{y}$ de intenso intercambio transfronterizo, es más fácil que las escritoras se solidaricen y busquen la colectividad. Es indudable que entre ellas también ha habido contiendas literarias, palabras hirientes, polémicas. La tensión entre dos grandes escritoras latinoamericanas del siglo XX, Marta Brunet y Gabriela Mistral, es conocida. Pero también lo es la amistad y por supuesto las invocaciones literarias. Siguiendo con el campo literario chileno, es muy importante la posta que se produce cuando Diamela Eltit rescata, en el 2000, a María Carolina Geel del prólogo abusivo de Alone a su Cárcel de mujeres; o que en 1949, cincuenta años antes, la misma María Carolina Geel revalorice en su ensayo Siete escritoras chilenas el trabajo de Gabriela Mistral, María Luisa Bombal, Marta Brunet, Amanda Labarca, María Monvel, Chela Reyes y Luz de Viana.

Vuelvo sobre el texto de Marta Sanz en el Tsunami español para destacar este aspecto genealógico, que resulta fundamental: "las mujeres nos estamos pensando [... Nos pensamos todas, de un modo intergeneracional [...] Escarbamos dentro del ombligo porque ese ombligo se une a otros a través de un cordón que configura una genealogía. De manos, pies y cuerpos castigados por el trabajo, el

\footnotetext{
${ }^{12}$ Me refiero a esto con más detalle en el capítulo "Autoría femenina y autoficción en la narrativa latinoamericana reciente". En: Samperio, Daniel y Christian Sperling (Eds.). Desafios y Debates para el Estudio de la Literatura Contemporánea. Universidad Autónoma Metropolitana Azcapotzalco, México (en prensa).
} 
dominio, el silencio...". La palabra genealogía es relevada, entonces, en este contexto literario, visibilizando genealogías creativas hasta ahora parcialmente obliteradas.

En este sentido, hay bastante diferencia con lo que nos han enseñado las pedagogías literarias machistas. Quiero poner tan solo un ejemplo: en el mundo de la crítica literaria, es usual hablar de los parricidios literarios y convocar al Edipo literario. Debiera parecernos "natural” leer en una caracterización de los escritores de los 90 o del boom como autores deseosos de "matar" a sus padres literarios. Los latinoamericanos, además, son "calibanescos" (Avelar 1999), porque asesinan al padre colonialista europeo encarnado por Próspero. Es cierto que ambos términos refieren a generaciones notoriamente masculinas y misóginas. Pero si hubiera tan solo una mujer, ¿habría que asumir que su escritura revela marcas, motivaciones y retóricas similares a éstas, con el signo "universal" de Edipo? La cultura judeocristiana también provee de metáforas a los críticos y es también común que se utilice el calificativo de "adánicos", para hablar de autores fundacionales. Hasta aquí no he tenido noticia de escritoras "évicas" o "lilíticas", tal vez porque nadie escribe para, como nos han enseñado, sentirse culpable por la expulsión del paraíso. Se sabe, además, que las mitologías y el archivo de imágenes “occidental” no reconoce positivamente a las mujeres. Como escribe Nuria Barros en "María Pandora" (Tsunami español):

Pandora, la Eva griega, ha pasado a la literatura como la primera de las mujeres asociadas a las fuerzas oscuras, el mal, la desgracia: Eva, Helena de Troya, Medea, Circe... A ellas se suman un sinfín de estereotipos establecidos por el discurso narrativo históricamente dominante: Penélope o el apolillado mito de la fidelidad conyugal; Casandra o el cruel mito de la lucidez femenina tachada de locura; las Sirenas, esos seres mitad mujeres mitad pájaros, que tanto recuerdan a las brujas en su sabiduría y en el odio que siempre han suscitado en los hombres; Eurídice, una más 
de la larga lista de personajes femeninos secundarios que la literatura utiliza para realzar a los personajes masculino. (164-165)

Pandora, Circe, Eva, Casandra, las brujas... Lejos de querer "matarlas", lo más probable es que nos encontremos con autoras que buscan reivindicarlas. Las escritoras no necesitan matar a nadie. Por el contrario, una y otra vez recomponen las matrices, el tejido roto, escondido, guardado entre anaqueles, de una posible genealogía literaria.

\section{Comunalistas}

En las últimas dos décadas se intensifica la demanda por visibilizar a comunidades, como ya se ha dicho, "en estado de resistencia". Enfatizo el carácter colectivo de estas demandas, que ha sido clave no solo en la visibilización de las propuestas feministas sino que también constituye una respuesta al exacerbado individualismo activado por el necrocapitalismo y las pulsiones del consumo y el espectáculo. ¿Cómo se puede responder a la normalización de la competencia y las imposiciones del mercado desde la escritura? En un examen del actual escenario, María José Punte, Laura Arnés y Lucía de Leone, en su introducción al volumen "En la intemperie. Poéticas de la fragilidad y la revuelta" de la Historia Feminista de la Literatura Argentina ${ }^{13}$, proyecto que instala recorridos y lecturas que cuestionan el canon literario de ese país, describen lo que ellas llaman "un tiempo de poéticas de lo colectivo, de modulaciones discursivas que van desde el susurro hasta el griterío ensordecedor", en que la experiencia corporizada

ya no se entiende como individual, porque lo que se suma al sensorium es la comprensión de la precariedad. Y es que justo ahí, donde los cuerpos

\footnotetext{
${ }^{13}$ Se proyectan seis volúmenes y un diccionario de autorxs con propuesta feminista, bajo la dirección de Nora Domínguez, María José Punte y Laura Arnés.
} 
individuales y colectivos se afectan en los contactos y agenciamientos que propician, la posibilidad de acción se incrementa. Justo ahí, donde el sexo y el texto se cruzan y los géneros se confunden. En ese punto en el que la literatura atraviesa los límites de la letra y se hace carne, grito y rostro; en ese instante en que la letra se niega a ser objeto estético pasivo, brilla la revuelta: desorden en el que la dirección cambia de forma pronunciada. $(17-18)$

Un frente común de escrituras que responde a las inquietudes del feminismo, desestabiliza la idea de lo "literario" (finalmente construida, incluso en sus fisuras, desde el canon) y plantea una posibilidad de agencia de subjetividades/cuerpos/voces que se resisten a su normalización y estandarización. Los ecofeminismos y formas recientes de militancia en el espacio latinoamericano han hecho hincapié en otras formas de integrar subjetividad y mundo, haciendo acopio de tramas complejas que buscan desjerarquizar las experiencias y comprender de otro modo las materialidades. Lo pasivo/activo es reconsiderado desde matrices no binarias y más integradoras de lo que implica el afecto, la percepción y el cambio. Entre los aportes de más impacto, y para seguir en una relación de contigüidad con las reflexiones sobre sororidad y genealogía, se encuentra la reformulación de lo comunitario, con base en experiencias que dicen relación no solo con la filosofía de autores como Jean-Luc Nancy o Maurice Blanchot, sino también con una serie de observaciones situadas, acerca del mundo estético y político de los pueblos originarios y las formas de trabajo comunitario muchas veces propiciados por mujeres.

María Lugones plantea que no es posible resistir a la colonialidad del género en soledad: "Una se resiste a ella desde dentro de una forma de comprender el mundo y de vivir en él que es compartida [...] Las comunidades más bien que los individuos hacen posible el hacer; una hace con otro/otra, no en aislamiento individual" (116). Diversos colectivos de mujeres, no solo en el mundo del arte (como "Mujeres creando", en Bolivia, o recientemente, en Chile, "LasTesis"), sino 
de muy distintos signos, como las feministas indígenas, las feministas comunitarias y campesinas, están trabajando en contra de la violencia ejercida por transnacionales, policías, narcoestados, buscando despatriarcalizar y descolonizar la vida cotidiana a través de marcos de acción anticapitalista. Lugones se refería a estas luchas, hace unos años ya, como "la afirmación de la vida por encima de la ganancia, el comunalismo por encima del individualismo, el "estar" por encima de la empresa, seres en relación en vez de divisiones dicotómicas una y otra vez en fragmentos organizados jerárquica y violentamente" (116). En el ámbito literario es también posible encontrar la reivindicación de otras formas de trabajo (disolviendo incluso la noción de "autoría") en muchos de los textos publicados en los últimos años; la importancia que han ido cobrando publicaciones alternativas como los fanzines, las ediciones cartoneras o algunas plaquettes literarias habla de estas nuevas formas de trabajo.

En la antología Avisa cuando llegues (2018) cuya versión digital gratuita se ha hecho para que "circule por calles, micros, liceos, colegios, oficinas, y todos los lugares donde haga falta" y que surge de un encargo de ONU Mujeres para pensar las experiencias de las mujeres en el espacio público, participan Yosa Vidal, Alia Trabucco, Marcela Trujillo, Luz María Astudillo, Alicia Scherson, Alejandra Moffat, Carla Zúñiga, Betina Keizman, Rosabetty Muñoz, Lina Meruane, Daniela Catrileo, Macarena Urzúa, Nina Avellaneda, Flavia Radrigán, Pía Barros, Natalia Figueroa, Verónica Jiménez, Begoña Ugalde, Carmen García, Ana María Baeza, Mónica Drouilly, Florencia Smiths, Juana Inés Casas, María Antonieta Contreras y Elvira Hernández. Las dos editoras del libro coinciden en subrayar el carácter colectivo de su enunciación. Carolina Melys asume un ideario colectivo que asocia a las marchas y movilizaciones de los últimos años: "hemos tenido que encontrar mecanismos para enfrentarnos a la calle. Tal vez uno de los mayores méritos de la salida masiva de las mujeres en multitudinarias marchas ha sido no solo el carácter fuertemente vindicativo, sino la configuración de un colectivo con objetivos comunes" (24). Y Alejandra Costamagna subraya el carácter coral del volumen: 
En este compilado de veinticinco autoras, que va desde dramaturgas a cantoras, de cineastas a poetas, de narradoras a ilustradoras, hemos querido armar un coro. Ramas diversas de un mismo arbusto en la mitad de la vía pública. Podemos hilar un manual de conducta a varias voces. (8)

Por mencionar solo un ejemplo, la poeta Rosabetty Muñoz, en el texto "Apnea", "se hunde" en el "cuerpo de agua" (79) que conforman las voces de otras mujeres en el archipiélago de Chiloé, en el sur de Chile:

Hablan poco, entrecortadas, en voz baja, se preliegan, doblan el cuerpo y echan los hmbros hacia adelante, como para proteger(se). Las frases que pronuncian son mínimas, oraciones breves, lugares comunes. A menudo monosílabos, o solo movimientos de cabeza. Lo que no se dice está bajo capas de ocultamiento; mientras más profundamente se hallan, más cerca de la cruda experiencia, menos palabras hay para decirlas. Lo oral, volátil como es, nos ofrece pistas para ir rastreando esta materia. He tratado de recoger las huellas verbales del no decir, del ocultamiento, del encubrir. (79)

El resultado de este ejercicio, efectuado por la poeta en 2017, con la participación de Sonia Muñoz, es un sutil montaje de frases de diverso tamaño y tipografía, una polifonía que da cuenta del silencio persistente, de las crueldades y afectos por los que puede atravesar la experiencia femenina en el espacio de sus relaciones, sobre todo en un ambiente insular y semi rural.

Hacia este tipo de experiencias de encuentro y escritura apunta Cristina Rivera Garza en el potente libro de ensayos Los muertos indóciles, en que describe la importancia que han adquirido en los últimos años procesos de escritura dialógicos que trabajan la desapropiación, desplazando la autoría como eje dador de sentido: 
A esa práctica, por llevarse a cabo en condiciones de extrema mortandad y en soportes que van del papel a la pantalla digital, es a lo que empiezo por llamar necroescritura en este libro. A la poética que la sostiene sin propiedad, o retando constantemente el concepto y la práctica de la propiedad, pero en una interdependencia mutua con respecto al lenguaje, la denomino desapropiación. (21)

Rivera Garza se refiere al contexto de producción mexicano y a su experiencia con la cultura mixe y sus formas de trabajo comunalista, que ponen en cuestión el circuito del capital y de la autoría individual; la poética de la desapropiación "busca enfáticamente desposeerse del dominio de lo propio, configurando comunalidades de escritura que, al develar el trabajo colectivo de los muchos, como el concepto antropológico mixe del que provienen, atienden a lógicas del cuidado mutuo y a las prácticas del bien común" (21). No se trata aquí de "representar" a nadie (como lo hicieron lxs escritorxs latinoamericanos que exploraron el mundo indígena a lo largo del siglo XX, incluso aquellxs que tuvieron un programa "indigenista", o quienes buscaron construir figuras representativas en el marco de las literaturas nacionales). Ese paternalismo es abandonado para ir en busca de experiencias de escritura comunitarias, "y por comunidad aquí me refiero no sólo al entramado físico que constituyen el autor, el lector y el texto, sino también [...] a esa experiencia de pertenencia mutua; con el lenguaje y de trabajo colectivo con otros, que es constitutiva del texto" (22). ¿Más ejemplos de esto? Entre otros, el demoledor texto de Sara Uribe Antígona González, en que un trabajo de montaje de testimonios, voces y escrituras amplifica la experiencia de la violencia mexicana a través de la trágica figura griega.

El mundo se haya en una coyuntura en que las instituciones más arraigadas se han puesto en cuestión; el capitalismo en su "fase avanzada" fagocita las experiencias, enferma y produce la miseria de millones de personas, pero también de otras especies en extinción, así como la fragilidad del mundo como lo hemos conocido hasta hoy. En esta encrucijada los feminismos empujan transformaciones 
políticas y estéticas que van mucho más allá de las consignas más conocidas y nos invita a repensar las formas en que nos relacionamos y conceptualizamos nuestra experiencia en el mundo. Autoría, sororidad, comunalismo, genealogismo, desapropación son tan solo algunos de los conceptos que precisan ser discutidos, advirtiendo su complejidad política y estética.

\section{Bibliografía}

Abenshushan, Vivian. "Disolutas (a ante cabe con contra) las pedagogías de la crueldad”. En: VV. AA. Tsunami. Ed. y prólogo de Gabriela Jáuregui. México: Sexto Piso, 2018. Versión digital.

Amaro, Lorena; Punte, María José y Fernanda Bustamante. "Narradoras latinoamericanas de las últimas dos décadas: voces, representaciones, estrategias". Revista Letral n ${ }^{\circ} 22$ (2019): 1-12.

Amaro, Lorena. "Cómo se construye una autora. Algunas ideas para una discusión incómoda". En: Palabra pública, 24 de agosto de 2020. Web. https://palabrapublica.uchile.cl/2020/08/24/como-se-construye-unaautora-algunas-ideas-para-una-discusion-incomoda/

Arnés, Laura; De Leone, Lucia y María José Punte. "En la intemperie. Poéticas de la fragilidad y la revuelta". En Arnés, Laura; Domínguez, Nora y María José Punte (Directoras). Historia Feminista de la Literatura Argentina. Buenos Aires: Eduvim, 2020, 15-32.

Avelar, Idelber. Alegorías de la derrota. La ficción posdictatorial y el trabajo del duelo. Santiago de Chile: Cuarto Propio, 1999.

Barrientos, Mónica. “'No todas queríamos ser reinas'. La crítica, las autoras y las autorías". Palabra Pública, 5 de septiembre de 2020. Web. https://palabrapublica.uchile.cl/2020/09/05/no-todas-queriamos-serreinas-la-critica-las-autoras-y-las-autorias/

Barros, Nuria. "María Pandora". En: VV.AA. Tsunami. Ed. y prólogo de Marta Sanz. Madrid: Sexto Piso, 2019.

Biglieri, Paula y Luciana Cadahia. "We Populists are Feminists". Seven Essays on Populism. Medford: Polity Press, 2021, 115-132. 
Camacho, Estefanía. "A un año del \#MeTooEscritoresMexicanos". En:

Gatopardo, 25 de marzo de 2020. Web. https://gatopardo.com/noticiasactuales/me-too-escritores-mexicanos-acoso-sexual/

Costamagna, Alejandra. "A la vuelta de la esquina". En: VV.AA. Avisa cuando llegues. Edición y prólogos de Alejandra Costamagna y Carolina Melys. Santiago de Chile: Bifurcaciones, 2018, 7-17.

Curiel, Ochy. "Descolonizando el feminismo: una perspectiva desde América Latina y el Caribe". Primer Coloquio Latinoamericano sobre Praxis y Pensamiento Feminista, Junio 2009, Buenos Aires. https://repositorio.unal.edu.co/handle/unal/75231?show=full

De la Cerda, Dahlia. "Feminismo sin cuarto propio". En: VV.AA. Tsunami II. Edición y prólogo de Gabriela Jáuregui. México: Sexto Piso, 2020, 5998.

Domínguez, Nora. "Salidas de madre para salirse de madre". En: Revista Iberoamericana, Vol. LXIX, Núm. 202 (2003): 165-181.

Eltit, Diamela. "Los bordes de la letra". Web. En: http://www.letras.mysite.com/eltitcuba0808031.htm . "Mujeres que matan.” En: Geel, María Carolina. Cárcel de mujeres. Santiago de Chile: Cuarto Propio, 2000.

Freixas, Laura (Ed. y prólogo). Madres e hijas. Barcelona: Anagrama, 1996.

Geel, María Carolina. Siete escritoras chilenas. Santiago de Chile: Rapa Nui, 1949.

Giunta, Andrea. Feminismo y arte latinoamericano. Historias de artistas que emanciparon el cuerpo. Buenos Aires: Siglo XXI Editores, 2018.

Jáuregui, Gabriela. "Desde Neplanta hablamos". VV. AA. Tsunami. Ed. y prólogo de Gabriela Jáuregui. México: Sexto Piso, 2018. Libro digital. . "Herramientas desobedientes". VV. AA. Tsunami. Ed. y prólogo de Gabriela Jáuregui. México: Sexto Piso, 2018. Libro digital. . "El cuerpo en la línea". VV.AA. Tsunami II. Ed. y prólogo de Gabriela Jáuregui. México: Sexto Piso, 2020.

Kottow, Andrea y Ana Traverso. Escribir \& tachar. Narrativas escritas por mujeres en Chile (1920-1970). Santiago de Chile: Ediciones Overol, 2020.

Locane, Jorge. "Por una sociología de las ausencias en la literatura mundial". EN: Müller, Gesine, Jorge Locane y Benjamin Loy. Writing, Book Markets and Epistemologies between Latin America and the Global South. Berlín: De Gruyter: 2018.

Lugones, María. "Hacia un feminismo descolonial". En: La manzana de la discordia vol.6 n² (2011): 105-119. 
Melys, Carolina. "Salir solas”. En: VV.AA. Avisa cuando llegues. Ed. y prólogos de Alejandra Costamagna y Carolina Melys. Santiago de Chile: Bifurcaciones, 2018, 19-25.

Muñoz, Rosabetty. “Apnea”. En: VV.AA. Avisa cuando llegues. Ed. y prólogos de Alejandra Costamagna y Carolina Melys. Santiago de Chile: Bifurcaciones, 2018, 79-84.

Pérez, Aina, Meri Torras y Elena Cróquer, “A manera de presentación. Ninguna voz es transparente. Autorías de mujeres para un corpus visibilizador", en Mundo Nuevo. Revista de Estudios Literarios. Dossier "Autoría y Género", año VII, n. 16, 2015, pp. 15-27.

Pérez, Aina y Meri Torras. "El género de la autoría". En: Pérez, Aina y Meri Torras (Eds.). ¿Qué es una autora? Encrucijadas entre género y autoría. Barcelona: Icaria, 2019, 7-24.

Enriquez, Mariana. “Las pesadillas de Mariana Enriquez". Latercera.com. 23 junio, 2018, https://www.latercera.com/paula/las-pesadillas-marianaenriquez/

Richard, Nelly. Feminismo, género y diferencia(s). Santiago de Chile: Palinodia, 2008.

Rivera Garza, Cristina. "La primera persona del plural”. En: VV. AA. Tsunami. Ed. y prólogo de Gabriela Jáuregui. México: Sexto Piso, 2018. Libro digital.

. Los muertos indóciles. Santiago de Chile: Los libros de la mujer rota, 2020.

Sanz, Marta. "Prólogo. Afónica”. En: VV.AA. Tsunami. Ed. y prólogo de Marta Sanz. Madrid: Sexto Piso, 2019, 9-21.

Uribe, Sara. Antigona González. Valparaíso: Ediciones Libros del Cardo, 2020.

Vial, Juan Manuel. "Hembras de armas tomar". La Tercera, 18 de julio de 2015. Web. https:/www.latercera.com/voces/hembras-de-armas-tomar/

VV.AA. Avisa cuando llegues. Ed. y prólogos de Alejandra Costamagna y Carolina Melys. Santiago de Chile: Bifurcaciones, 2018. . Cien años, cien libros de escritoras en español. Número especial de Revista Arcadia, diciembre de 2019. http://especiales.revistaarcadia.com/los-cien-mejores-librosrecomendados-de-los-ultimos-cien-anos-escritos-por-mujeres/index.html . Salidas de madre. Prólogo de Alejandra Rojas. Santiago de Chile: Planeta, 1997. .AA. Salirse de madre. Idea y coordinación de Hilda Rais. Buenos Aires: Croquiñol, 1989. 
CATEDRAL TomADA: Revista de crítica literaria latinoamericana / Journal of Latin American Literary Criticism En estado de resistencia: la reciente narrativa hispanoamericana de mujeres

. Tsunami. Ed. y prólogo de Gabriela Jáuregui. México: Sexto Piso, 2018. Libro digital.

. Tsunami II. Ed. y prólogo de Gabriela Jáuregui. México: Sexto Piso, 2020.

. Tsunami. Ed. y prólogo de Marta Sanz. Madrid: Sexto Piso, 2019. 